\title{
Protein synthesis and secretion in human mesenchymal cells derived from bone marrow, adipose tissue and Wharton's jelly
}

\author{
Paola Romina Amable ${ }^{1 * \dagger}$, Marcus Vinicius Telles Teixeira ${ }^{1,2 \dagger}$, Rosana Bizon Vieira Carias ${ }^{1,2}$,
} José Mauro Granjeiro ${ }^{2}$ and Radovan Borojevic ${ }^{1,2}$

\begin{abstract}
Introduction: Different mesenchymal stromal cells (MSC) have been successfully isolated and expanded in vitro and nowadays they are tested in clinical trials for a wide variety of diseases. Whether all MSC express the same cell surface markers or have a similar secretion profile is still controversial, making it difficult to decide which stromal cell may be better for a particular application.

Methods: We isolated human mesenchymal stromal cells from bone marrow (BM), adipose tissue (AT) and Wharton's jelly (WJ) and cultured them in fetal bovine serum supplemented media. We evaluated proliferation, in vitro differentiation (osteogenic, adipogenic and chondrogenic potential), expression of cell surface markers and protein secretion using Luminex and ELISA assays.

Results: Cell proliferation was higher for WJ-MSC, followed by AT-MSC. Differences in surface expression markers were observed only for CD54 and CD146. WJ-MSC secreted higher concentrations of chemokines, pro-inflammatory proteins and growth factors. AT-MSC showed a better pro-angiogenic profile and secreted higher amounts of extracellular matrix components and metalloproteinases.

Conclusions: Mesenchymal stromal cells purified from different tissues have different angiogenic, inflammatory and matrix remodeling potential properties. These abilities should be further characterized in order to choose the best protocols for their therapeutic use.
\end{abstract}

\section{Introduction}

Mesenchymal stromal cells (MSC) are a small population of multipotent progenitor cells present in nearly all human tissues, being mostly found in the perivascular niche [1]. MSC were first isolated from bone marrow [2], but they have been obtained subsequently from a wide variety of fetal and adult tissues: adipose tissue [3], placenta [4], lung [5], umbilical cord [6], synovial membrane [7] and dental pulp [8] among many others.

Regenerative medicine makes use of MSC and of their multipotent properties to promote tissue regeneration. MSC are able to migrate into injured tissues, engraft and differentiate into many cell types, participating thus directly

\footnotetext{
* Correspondence: pramable@gmail.com

${ }^{\dagger}$ Equal contributors

'Excellion Biomedical Services S.A, Rua Afrânio de Mello Franco 333, 25651000 PetrópolisRio de Janeiro, Brazil

Full list of author information is available at the end of the article
}

in tissue repair and regeneration [9]. They also secrete paracrine mediators, reducing inflammation and accelerating tissue regeneration by activation of resident stem cells and mobilization of circulating systemic stem cells through chemotactic signaling $[10,11]$. Clinical trials have already confirmed that use of MSC is safe and effective [12]. Even when MSC express major histocompatibility complex class I, they proved to be safe in allogeneic transplants, also between HLA-incompatible individuals, since they do not elicit alloreactive lymphocyte proliferative responses in vitro, they produce locally immunomodulatory proteins and their expression levels of major histocompatibility complex class II are negligible [13,14].

Studies comparing MSC derived from different tissues are limited to in vitro and pre-clinical studies. Clinical trials are generally focused on safety and efficiency of a therapy using a specific type of MSC, without demonstrating which MSC is the best for each therapy, or even 
justifying why a specific cell type was believed to be the best option. Basic MSC comparative studies are required to better understand MSC properties and abilities, indicating the most appropriate MSC type for a particular clinical application.

In vitro studies have already shown that MSC from different origins varied when considering differentiation potential: some cells are better for differentiation into osteoblast-like cells [15], while synovium-derived MSC and umbilical cord-derived MSC are better differentiated into chondrocytes than the bone marrow-derived MSC $[16,17]$. MSC isolated from fetal tissues are superior regarding cardiomyocyte and endothelial cell differentiation when compared to adult tissue-derived MSC [18].

Besides differentiation potential, recent studies have approached other MSC attributes that allowed a deeper understanding of tissue-derived properties. Hsieh and colleagues compared MSC derived from Wharton's Jelly and bone marrow regarding their ability to regenerate infarcted myocardia; they described secretome differences that make Wharton's Jelly-derived MSC a more angiogenic, neuroprotective and neurogenic option [19]. Naftali-Shani and coworkers carried out a pre-clinical trial of myocardial infarction in rats comparing the effects of human stromal cells obtained from four locations (epicardial fat, pericardial fat, subcutaneous fat and the right atrium) and they showed that hMSCs from epicardial fat and the right atrium secreted the highest amounts of trophic and inflammatory cytokines in vitro, expressed higher amounts of inflammation- and fibrosis-related genes in vitro and impaired heart recovery in vivo [20]. Research studies like these mentioned here are essential for determining the best tissue-derived mesenchymal stromal cell for a particular regenerative therapy strategy.

In the present study, we compared three different cell types: MSC derived from bone marrow, adipose tissue and Wharton's Jelly with the purpose to better understand their differences and similarities. We monitored proliferation, differentiation into mesodermal cell types and cell surface marker expression. We also quantified production and secretion of cytokines, chemokines, growth factors and extracellular matrix components into the cell culture supernatants.

\section{Methods}

\section{Ethics statements}

All the experimental procedures were done after Ethics Research Committees approval and all donors signed an informed consent. Adipose tissue-derived MSC (ATMSC) were obtained from abdominal liposuction during plastic surgery (age: $53.8 \pm 5.4$ years; sex: $50 / 50 \%$ male/ female; CEP No. 55219/12, Research Ethics Committee of Pro-Cardíaco Hospital, Rio de Janeiro, Brazil). Wharton's Jelly-derived MSC (WJ-MSC) were obtained from umbilical cords of full-term cesarean births (38 to 39 weeks; CEP No. 336/10, Research Ethics Committee of Pro-Cardíaco Hospital, Rio de Janeiro, Brazil). Bone marrow-derived MSC (BM-MSC) were purified from bone marrow harvested from posterior iliac crests during orthopedic surgery (age: $55.5 \pm 13.4$ years; sex: 50/50\% male/female; CEP No. 473/12, Research Ethics Committee of Pro-Cardíaco Hospital, Rio de Janeiro, Brazil).

\section{Cell isolation and culture}

Stromal cells were isolated as previously described [21]. Briefly, nucleated cells were separated from human bone marrow using Ficoll-Paque ${ }^{\mathrm{Tm}}$ PLUS (GE Healthcare, Uppsala, Uppsala, Sweden, \#17-1440-02) by density gradient centrifugation at $700 \mathrm{~g}$ during a 15 -minute period. After washing cells with phosphate-buffered saline (PBS LGC, Cotia, São Paulo, Brazil, \#13-30259-05), they were plated in T25 flasks in alpha-Minimum Essential Medium ( $\alpha$-MEM - LGC, BR30007-05) supplemented with 10\% fetal bovine serum (FBS - LGC, \#10-BIO-500). Human adipose tissue was washed three times with PBS and was treated with $1.76 \mathrm{mg}$ collagenase type I/gram tissue (Sigma-Aldrich, St. Louis, Missouri, USA, C9891) for 30 minutes at $4^{\circ} \mathrm{C}$ and 30 minutes at $37^{\circ} \mathrm{C}$ with agitation. After proteolytic activity inhibition and centrifugation (700 $g$, seven minutes), pelleted cells were plated in T25 flasks. Human umbilical cords were washed with PBS and blood vessels were removed. Wharton's jelly was cut into small pieces and digested with $0.9 \mathrm{mg}$ collagenase type II/gram tissue (Sigma, C6885) at $37^{\circ} \mathrm{C}$ for one hour. Washed cells were centrifuged at $700 \mathrm{~g}$ for seven minutes and plated in T25 flasks. All cells were expanded up to passage number 3 in order to obtain a higher number of cells and were then cryopreserved.

For all the experiments, cells obtained from four different donors in the same passage number were thawed and mixed in order to prepare cell pools, which were immediately plated for proliferation experiments.

\section{Proliferation curves}

Cells of each cell pool were seeded in 24-well plates at a concentration of 6,000 cells/mL in $\alpha$-MEM supplemented with $10 \%$ FBS. Cells grown in different wells were trypsinized and counted in a Neubauer hemocytometer at three different times: 96, 144 and 192 hours.

\section{Flow cytometry}

After cell detachment using a $0.125 \%$ trypsin solution, cells were washed with PBS and resuspended in PBS containing $2 \%$ FBS. Cell concentration and viability were monitored using Trypan blue in a Neubauer hemocytometer. The following monoclonal antibodies were used as indicated by the manufacturers (BD Pharmingen ${ }^{\circ}$ (BD, Franklin Lakes, New Jersey, USA)): CD90-PE 
(BD, \#555596), CD73-FITC (BD, \#561254), CD105-FITC (BD, \#561443), CD45-FITC (BD, \#347463), CD14-PE (BD, \#555398), CD34-PEcy5 (BD, \#561819), CD31-PE (BD, \#555446), IgG-FITC (BD, \#555786), HLA-DR-FITC (BD, \#555558), CD166-PE (BD, \#560903), CD44-PE (BD, \#555479), CD54-PEcy5 (BD, \#555512), CD146-PE (BD, \#559263). Isotype controls were used for determining nonspecific binding and defining cut-off values. A minimum of 20,000 events were acquired on a BD FACS Calibur $^{\circledR}$ flow cytometer and results were analyzed using CellQuest $^{\mathrm{TM}}$ software.

\section{Differentiation assays}

Pre-cultured cells were seeded into 24 -well plates $(1 \mathrm{~mL} /$ well $)$ at 13,157 cells $/ \mathrm{cm}^{2}$ (adipogenic differentiation), 5,263 cells $/ \mathrm{cm}^{2}$ (osteogenic differentiation) or cultured as pellets containing $1 \times 10^{5}$ cells (chondrogenic differentiation). Differentiation medium was replaced twice a week.

\section{Adipogenic medium}

LG-DMEM supplemented with 10\% FBS, $1 \mu \mathrm{M}$ dexamethasone, $0.5 \mathrm{mM}$ 3-Isobutyl-1-methylxanthine, $10 \mu \mathrm{M}$ human insulin (Humulin- $\mathrm{N}^{\bullet}$, Eli Lilly and Company, Indianapolis, Indiana, USA), $0.2 \mathrm{mM}$ indomethacin and a penicillin/ streptomycin solution at $100 \mathrm{U} / \mathrm{mL}$ and $100 \mu \mathrm{g} / \mathrm{mL}$, respectively.

\section{Osteogenic medium}

LG-DMEM supplemented with 10\% FBS, $10 \mathrm{nM}$ dexamethasone, $10 \mathrm{mM} \beta$-glycerophosphate, $50 \mu \mathrm{M}$ L-ascorbic acid 2-phosphate and penicillin/streptomycin (all reagents obtained from Sigma-Aldrich, St. Louis, Missouri, USA) at $100 \mathrm{U} / \mathrm{mL}$ and $100 \mu \mathrm{g} / \mathrm{mL}$, respectively.

\section{Chondrogenic medium}

LG-DMEM supplemented with 1\% FBS, $50 \mu \mathrm{g} / \mathrm{mL}$ Lascorbic acid 2-phosphate, $10 \mathrm{ng} / \mathrm{mL}$ transforming growth factor- $\beta 3,0.169 \mathrm{UI} / \mathrm{mL}$ human insulin and $6.25 \mu \mathrm{g} / \mathrm{mL}$ human transferrin.

After 17 to 21 days, cell cultures were fixed in formalin buffer and washed with PBS. Intracellular accumulated lipids were stained with $0.5 \%$ Oil Red O solution. Calcium deposits were stained with $1 \%$ Alizarin Red S solution, pH 4.2. Glycosaminoglycans were stained with $1 \%$ toluidine blue solution.

\section{Cytokine, growth factor and extracellular matrix quantification}

We quantified cell supernatant concentration of 49 different cytokines, growth factors and extracellular matrix-related proteins: pro-inflammatory cytokines (GM-CSF, IL-1 $\beta$, IL-6, IL-8, TNF- $\alpha$, IFN- $\gamma$, IL-2, IL-2R, IL-7, IL-12p40/p70, IL-15 and IL-17), anti-inflammatory cytokines (IL-1RA, IL-4, IL-5, IL-10, IL-13 and IFN- $\alpha$,), chemokines (eotaxin, IP-10, MCP-1, MIG, MIP-1 $\alpha$, MIP-1 $\beta$ and RANTES), angiogenic growth factors (VEGF, VEGF-D, endostatin, aFGF, thrombospondin-2, angiopoietin-1, angiogenin and PLGF), matrix metalloproteinases (MMP-1, $-3,-7,-8$ and -13) and growth factors (EGF, HGF, bFGF, G-CSF, TGF- $\beta 1$, TGF- $\beta 2$, TGF- $\beta 3$, PDGF-AA, PDGF-AB, PDGF-BB and IGF-1). Commercial Luminex kits were used: Human Cytokine 30-plex Assay (Invitrogen, Carlsbad, California, USA), Fluorokine MAP TGF- $\beta$ Multiplex Kit (R\&D, Minneapolis, Minnesota, USA), Human Angiogenesis Fluorokine Multi Analyte Profiling Kit (R\&D, USA), Fluorokine MAP Human MMP kit (R\&D, USA) and Milliplex MAP Human IGF-1 Single Plex Kit (Millipore, Billerica, Massachusetts, USA). Only PDGF-AB was quantified using an ELISA kit: Quantikine hPDGF-AB ELISA (R\&D, USA). Procedures were performed according to the manufacturers' instructions.

Extracellular matrix proteins were also quantified in supernatants using commercial ELISA kits and following the manufacturers' instructions: heparan sulphate (E0623h, EIAab, Wuhan, Hubei, China), aggrecan (E91908Hu, USCN, Wuhan, Hubei, China), decorin (E92127Hu, USCN, USA), elastin (E91337Hu, USCN, USA), laminin (E90082Hu, USCN, USA), perlecan (E82748Hu, USCN, USA), fibronectin (E90037Hu, USCN, USA) and collagens I (E90571Hu, USCN, USA), II (E90572Hu, USCN, USA), III (E90176Hu, USCN, USA), IV (E90180Hu, USCN, USA).

We analyzed cell supernatants obtained from proliferation experiments at Day 8 (end of the exponential growth phase). Quantified supernatants contained FBS, so FBSsupplemented media were also quantified. In order to make results comparable, concentrations were normalized by cell concentration and culture time, therefore expressing them in $\mathrm{pg} / 10^{6}$ cells/day.

\section{Statistical analysis}

Results were expressed as mean \pm standard deviation for at least three replicates. Statistical significance was assessed by one-way non-parametric analysis of variance followed by the Bonferroni test (to compare the three groups). $P$-values $<0.05$ were considered statistically significant. Statistical analyses were performed using the Prism 5.00 Software (GraphPad Software Inc., San Diego, California, USA).

\section{Results}

\section{Cell proliferation}

Proliferation curves are shown in Figure 1 and cumulative proliferation times are shown in Table 1. WJ-MSC showed a higher proliferation potential, achieving a final cell concentration four times higher than AT- and BM-MSC after eight days. A slight decrease in cell proliferation was observed for all cell types after nine days in culture, as expected since the number of cell doublings is increasing and cell culture media nutrients are slowly depleted. 


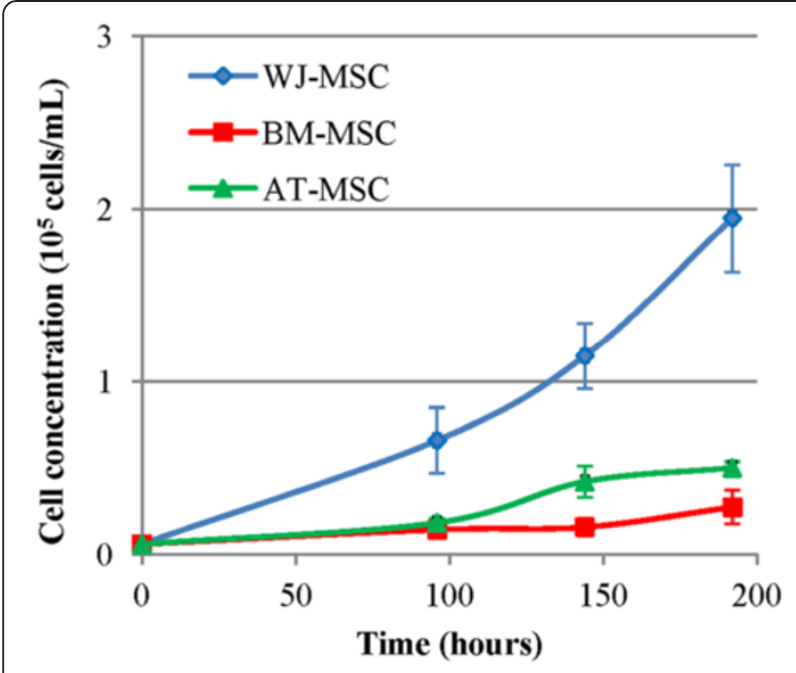

Figure 1 Proliferation curves of human mesenchymal stromal cells in a-MEM supplemented with $10 \%$ fetal bovine serum. BM-MSC: Bone marrow-derived mesenchymal stromal cells, AT-MSC: adipose tissue-derived mesenchymal stromal cells; WJ-MSC: Wharton's Jelly-derived mesenchymal stromal cells, a-MEM, alpha-Minimum Essential Medium.

It is well known that single "strong" clones can predominate in a long term culture of cell pools. Considering the duplication time of human MSC, an excessive proliferation of a single "strong" clone would take longer than the extension of our experiment, and we therefore assume that the pool is homogeneous during our eightday proliferation curve.

\section{Immunophenotyping}

Cell cultures in 10\% FBS-supplemented medium were analyzed regarding cell surface markers expression by flow cytometry. Results are shown in Table 2. Cell surface marker expressions were similar for all cell types, except CD54 and CD146. CD54 was expressed in $40.0 \pm$ $11.5 \%$ BM-MSC, $4.6 \pm 3.7 \%$ AT-MSC and $97.2 \pm 1.7 \%$ WJ-MSC. CD146 expression was higher for WJ-MSC

Table 1 Cumulative population doubling times for mesenchymal stromal cells grown in a-MEM supplemented with $10 \%$ FBS

\begin{tabular}{lccc}
\hline Time (hours) & BM-MSC & AT-MSC & WJ-MSC \\
\hline 96 & $79.5 \pm 16.1$ & $59.8 \pm 3.3$ & $28.4 \pm 3.6$ \\
144 & $79.7 \pm 2.1$ & $51.5 \pm 3.4$ & $34.0 \pm 1.8$ \\
192 & $88.4 \pm 8.1$ & $63.5 \pm 6.6$ & $38.4 \pm 1.7$ \\
\hline
\end{tabular}

Cell pools were plated in 24-well plates at a concentration of 6,000 cells $/ \mathrm{mL}$ and were trypsinized and counted after 96, 144 and 192 hours.

FBS: fetal bovine serum, a-MEM: alpha-Minimum Essential Medium, AT-MSC: adipose tissue-derived mesenchymal stromal cells, BM-MSC: bone marrow-derived mesenchymal stromal cells; WJ-MSC: Wharton's Jelly-derived mesenchymal stromal cells (WJ-MSC).
$(90.0 \pm 6.0 \%)$ and BM-MSC $(81.7 \pm 4.4 \%)$ and lower in AT-MSC (24.9 $\pm 3.4 \%)$.

\section{Cell differentiation}

All three cell types were differentiated into adipogenic, osteogenic and chondrogenic cell phenotypes (Figure 2). AT- and BM-MSC showed a higher adipogenic potential when compared to WJ-MSC. Regarding osteogenic potential, AT-MSC showed the highest calcium deposition, judging by Alizarin Red S staining. BM-MSC revealed a higher staining for glycosaminglycan with toluidine blue solution but pellet size was smaller than AT- and WJ-MSC.

\section{Cytokine, growth factor and extracellular matrix quantification}

Results from chemokine quantification in cell supernatant of MSC cultures are shown in Figure 3. Among the quantified chemokines, only MIG and MIP- $1 \alpha$ were not detected in any supernatant. RANTES was secreted only by AT- and WJ-MSC, with WJ-MSC secretion being 5.4 times higher than AT-MSC. AT- and BM-MSC did not secrete MIP-1 $\beta$ in detectable concentrations; only WJ-MSC secreted this chemokine, but in a low concentration $\left(1.8 \pm 1.3 \mathrm{pg} / 10^{6}\right.$ cells/day). MCP- 1 secretion was similar for BM- and AT-MSC and was significantly higher for WJ-MSC (WJ-MSC secretion was 17.2 and 9.6 times higher than BM- and AT-MSC, respectively). IP-10 secretion was also higher in WJ-MSC, but AT-MSC secreted the highest eotaxin concentration. Comparing all three cell lines, WJ-MSC secreted higher chemokine concentrations. BM-MSC secreted the lowest amount of all chemokines, suggesting a low capacity of cell mobilization into the tissue.

Considering anti-inflammatory cytokines, only IL-1RA was detected in all three cell types, with WJ-MSC secreting the highest concentration (35.2 and 3.7 times higher than BM- and AT-MSC, respectively; Figure 4). IFN- $\alpha$ was not secreted by AT- and BM-MSC in FBS-supplemented media in detectable concentrations; only WJ-MSC secreted $22.20 \pm 0.01 \mathrm{pg}$ IFN- $\alpha / 10^{6}$ cells/day. Therefore, WJMSC showed the stronger anti-inflammatory profile.

A total of 12 pro-inflammatory cytokines were quantified in all three cell culture supernatants. GM-CSF, TNF- $\alpha$, IFN- $\gamma$, IL-1 $\beta$, IL-2, IL-2R, IL-15 and IL-17 were not detected in any of them. WJ-MSC secreted the highest concentrations of IL- 6 and IL- 8 and AT-MSC the highest amounts of IL-7 and IL-12; BM-MSC secreted all four cytokines, but in a lower concentration. These results again confirmed the pro-inflammatory profile of WJ-MSC and the anti-inflammatory behavior of BMMSC. Results are shown in Figure 5.

The growth factors EGF, bFGF, TGF- $\beta 3$, PDGF-AB and IGF-1 were not detected in any supernatant, 
Table 2 Quantification of cell surface markers by flow cytometry

\begin{tabular}{lccc}
\hline Marker & BM-MSC & AT-MSC & WJ-MSC \\
\hline CD73 & $99.0 \pm 0.9(65.3 \pm 8.6)$ & $92.3 \pm 7.0(153.3 \pm 95.4)$ & $96.4 \pm 3.3(283.7 \pm 259.6)$ \\
CD90 & $98.3 \pm 0.8(125.9 \pm 63.6)$ & $97.0 \pm 3.1(203.6 \pm 94.7)$ & $99.5 \pm 0.4(295.4 \pm 79.2)$ \\
CD105 & $94.3 \pm 7.3(66.0 \pm 44.3)$ & $94.3 \pm 5.7(142.4 \pm 78.8)$ & $87.4 \pm 11.7(151.3 \pm 196.0)$ \\
CD45 & $0.8 \pm 0.9(3.5 \pm 1.6)$ & $0.6 \pm 0.7(11.3 \pm 11.0)$ & $1.1 \pm 1.1(7.9 \pm 3.8)$ \\
CD14 & $1.5 \pm 0.8(2.6 \pm 0.8)$ & $0.8 \pm 1.0(13.6 \pm 0.1)$ & $0.9 \pm 0.7(8.3 \pm 4.4)$ \\
CD34 & $0.7 \pm 0.6(2.8 \pm 1.6)$ & $0.7 \pm 0.9(2.6 \pm 2.1)$ & $2.6 \pm 2.7(8.7 \pm 4.7)$ \\
CD31 & $0.9 \pm 1.1(10.1 \pm 7.9)$ & $0.3 \pm 0.5(3.0 \pm 1.0)$ & $1.3 \pm 2.0(5.9 \pm 5.5)$ \\
CD44 & $99.6 \pm 0.2(233.2 \pm 58.1)$ & $99.3 \pm 0.1(1,036.0 \pm 1,306.4)$ & $95.6 \pm 5.4(231.7 \pm 118.3)$ \\
CD54 & $40.0 \pm 11.5(6.0 \pm 1.9)$ & $4.6 \pm 3.7(5.7 \pm 4.8)$ & $97.2 \pm 1.7(81.3 \pm 94.7)$ \\
CD146 & $81.7 \pm 4.4(26.5 \pm 24.4)$ & $24.9 \pm 3.4(38.9 \pm 10.6)$ & $90.9 \pm 6.0(110.4 \pm 48.4)$ \\
CD166 & $94.7 \pm 7.8(71.2 \pm 17.8)$ & $72.4 \pm 29.9(143.2 \pm 59.1)$ & $91.0 \pm 3.6(118.9 \pm 8.8)$ \\
HLA-DR & $1.8 \pm 2.4(6.0 \pm 6.3)$ & $1.1 \pm 1.2(29.1 \pm 17.9)$ & $1.1 \pm 1.1(8.0 \pm 3.2)$ \\
IgG & $0.7(8.24)$ & $0.6 \pm 0.0(7.3 \pm 5.1)$ & $0.6(22.8)$ \\
\hline
\end{tabular}

Results are expressed in mean percentage \pm standard deviation, with MPI values in brackets. AT-MSC: adipose tissue-derived mesenchymal stromal cells, BM-MSC: bone marrow-derived mesenchymal stromal cells, WJ-MSC: Wharton's Jelly-derived mesenchymal stromal cells.

meaning that their concentrations were lower than the detection limit of the corresponding assays. PDGF-AA was secreted by all cells under FBS-supplemented media (Figure 6). PDGF-BB was only secreted by BM-MSC, but in a low concentration $\left(1.6 \pm 0.8 \mathrm{pg} / 10^{6}\right.$ cells/day). Highest concentrations of HGF, TGF- $\beta 2$ and PDGF-AA were secreted by WJ-MSC. Best producers of TGF- $\beta 1$ were AT-MSC, but the difference with BM- and WJ-MSC secretion was not significant. G-CSF was secreted only by WJ-MSC at a rate of $28.8 \pm 9.1 \mathrm{pg} / 10^{6}$ cells/day. Considering the whole growth factor family here quantified, WJ-MSC showed the highest mitogenic profile.

Results regarding concentration of angiogenic factors in cell supernatants are shown in Figure 7. All the studied angiogenic factors were found in supernatants of the three cell types, except VEGF-D that was only detected in BM-MSC

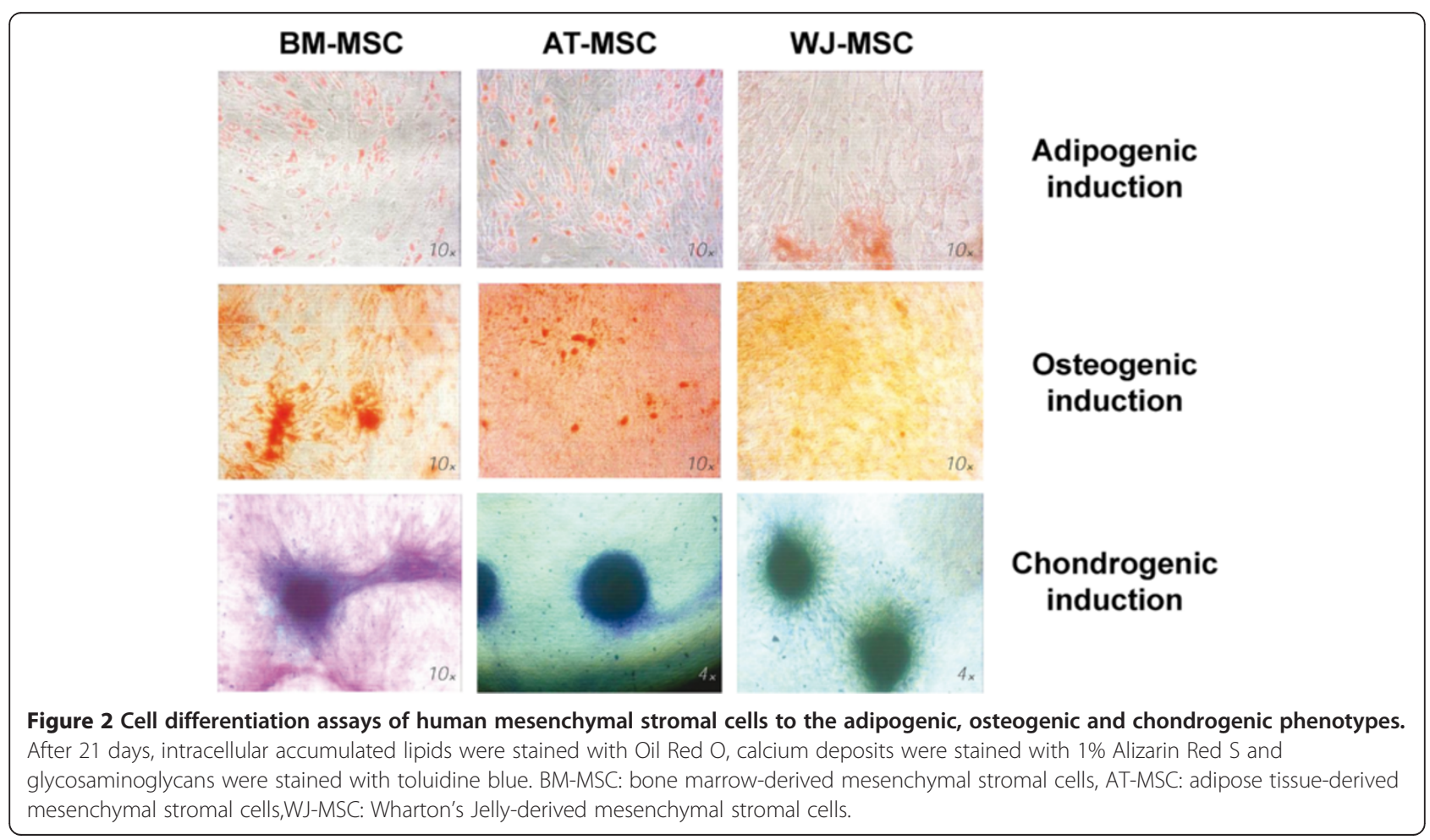




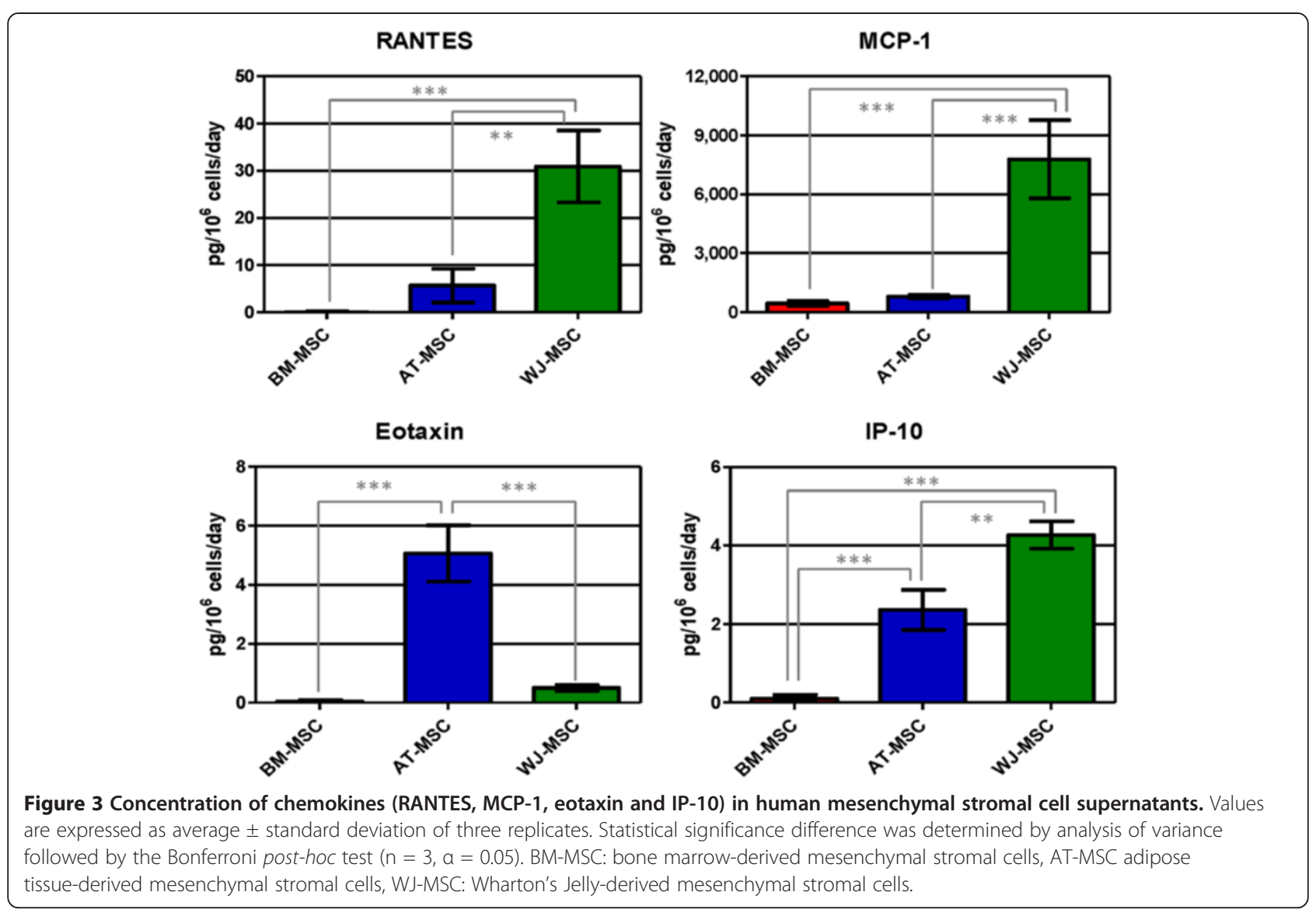

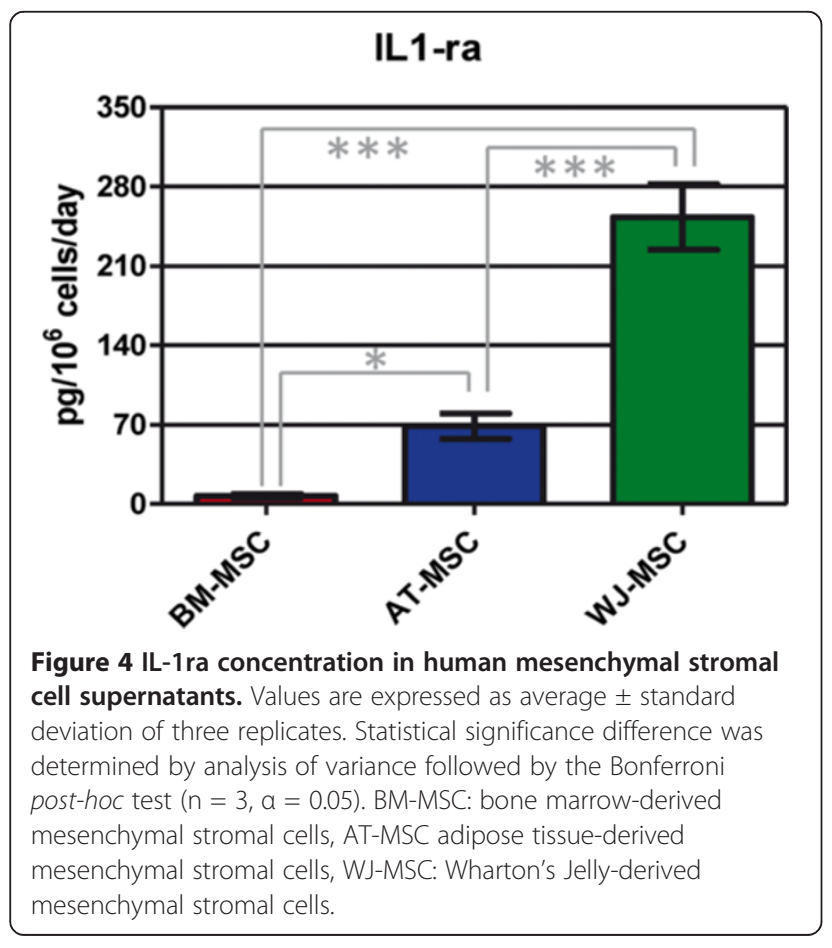

supernatants $\left(23.8 \pm 8.4 \mathrm{pg} / 10^{6}\right.$ cells/day). WJ-MSC secreted very low concentrations of VEGF, 4,070 and 4,614 times lower than BM- and AT-MSC, respectively. All three cell types showed similar angiopoietin-1 concentrations in their supernatants. AT-MSC secreted the highest amounts of angiogenin, PLGF and aFGF. Thrombospondin-2 secretion by WJ-MSC was 3.2 and 6.8 times higher than ATand BM-MSC, respectively, and endostatin concentration in WJ-MSC was also higher than AT- and BM-MSC (1.8 and 7.2 times, respectively). Considering these results we can conclude that BM-MSC have a lower angiogenic potential, and that AT- and WJ-MSC are more angiogenic but their effects might be different since they secreted a different panel of angiogenic factors.

All the studied extracellular matrix proteins were detected (Figure 8). AT-MSC secreted higher concentrations of collagen I, II and III. AT-MSC were also the only cell types able to secrete collagen IV at detectable concentrations $\left(190.1 \pm 48.8 \mathrm{pg} / 10^{6}\right.$ cells/day). Fibronectin was not detected in any supernatant. BM-MSC secreted significantly higher amounts of heparan sulfate. Elastin and aggrecan concentrations in BM-MSC supernatants were also higher than in AT- and WJ-MSC, but these differences were not statistically significant. WJ-MSC did not secrete decorin, laminin, fibronectin, heparan sulfate, collagen II 
IL-6

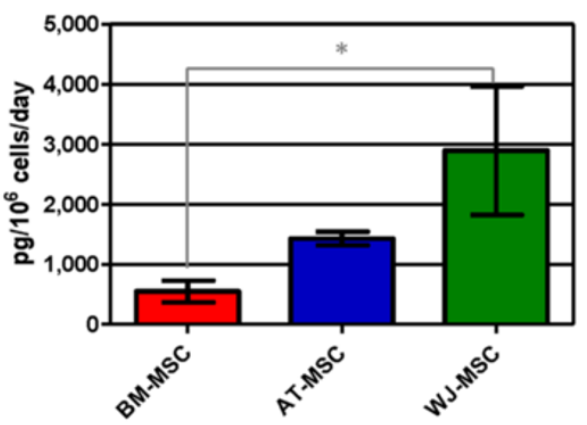

IL-8

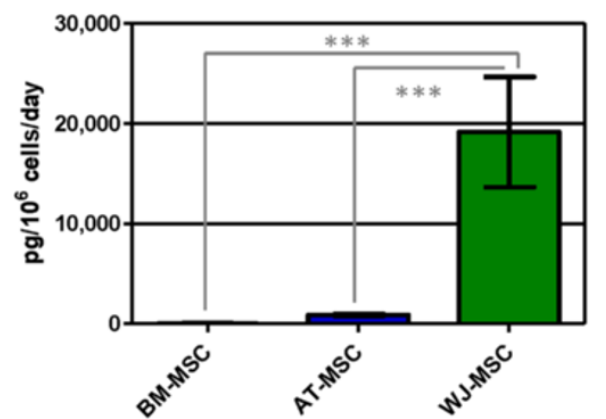

IL-7

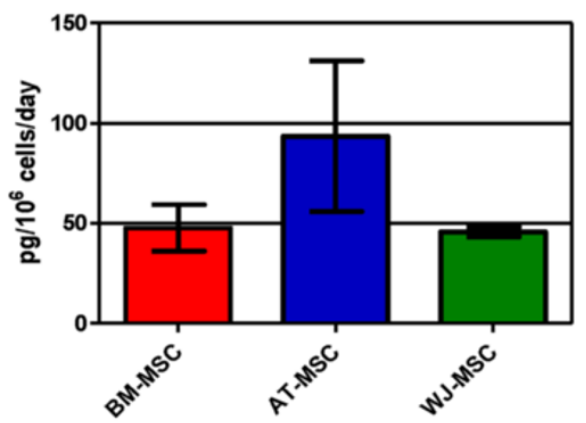

IL-12

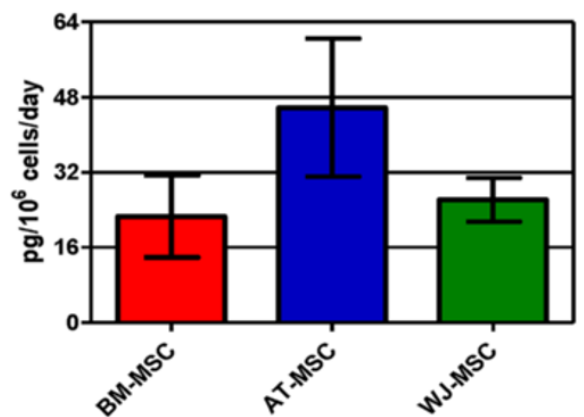

Figure 5 Concentration of secreted pro-inflamatory cytokines (IL-6, IL-7, IL-8 and IL-12) in mesenchymal stromal cell supernatants. Values are expressed as average \pm standard deviation of three replicates. Statistical significance difference was determined by analysis of variance followed by the Bonferroni post-hoc test $(n=3, a=0.05)$. BM-MSC: bone marrow-derived mesenchymal stromal cells, AT-MSC adipose tissue-derived mesenchymal stromal cells, WJ-MSC: Wharton's Jelly-derived mesenchymal stromal cells.

and IV and aggrecan in FBS-supplemented medium. Thus, AT-MSC are an excellent collagen-secreting cell type and WJ-MSC secrete a limited amount of extracellular matrix components.

Metalloproteinase concentrations are shown in Figure 9. AT-MSC secreted the highest concentrations of MMP1 (collagenase 1) and MMP3 (stromelysin 1). None of the three cell types secreted MMP7 (matrilysin). MMP8 (collagenase 2) was secreted by BM-MSC only $(50.3 \pm 16.8$ $\mathrm{pg} / 10^{6}$ cells/day). MMP13 (collagenase 3 ) secretion was only quantified in AT-MSC supernatants $\left(25.6 \pm 0.1 \mathrm{pg} / 10^{6}\right.$ cells/day).

Results from all proteins quantified are also shown in Additional file 1: Table S1.

\section{Discussion}

The present study was done to compare biological parameters of the three MSC isolated from the most frequently used tissue sources: bone marrow, adipose tissue and Wharton's Jelly of the umbilical cord, under the basal conditions of in vitro cell culture using synthetic media and fetal bovine serum. This first study is being pursued by in vitro analyses under conditions more closely representative of the in vivo tissue environments found in cell therapies using MSC. We describe the characterization of a representative range of secreted proteins by three mesenchymal stromal cells, isolated from different human tissues. The proposal is the selection of the most appropriate type of MSC for a specific therapy, since key characteristics are needed for the cells to effectively participate in tissue regeneration for a particular disease. For example, for cartilage-regenerating therapies, a cell secreting high amounts of cartilage-specific components of the extracellular matrix would be desired; ischemic diseases should be ideally treated with a cell showing antiinflammatory and pro-angiogenic potential, in order to control the inflammatory environment and to promote the re-vascularization of the affected area. Our results confirmed that mesenchymal cells derived from different origins have different properties in terms of pro-regenerative, pro-angiogenic or anti-inflammatory activities. Analyses of the behavior of the three different MSC studied here may indicate the good choice of the type of the MSC to be used in each therapy.

Nowadays, MSC are used in regenerative medicine in two contexts: autologous and allogeneic. In the former one, integration of MSC into the regenerating tissues is sought, and the capacity of proliferation and production 


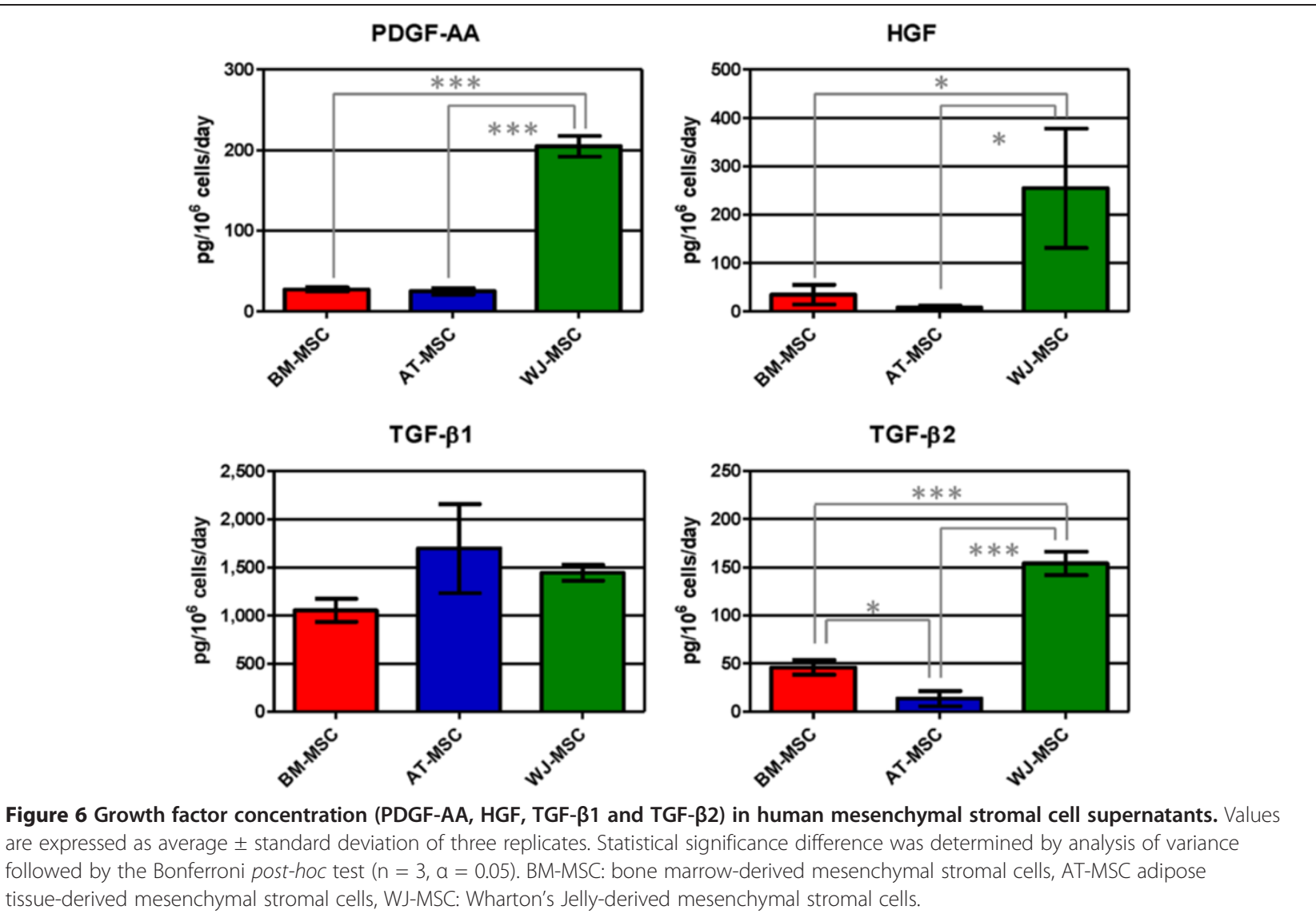

of extracellular matrix are relevant. In the latter one, a long term integration of MSC is not expected, even if MSC express only low levels of the histocompatibility markers. Their anti-inflammatory activity and their capacity to activate resident stem cells and mobilize the circulating ones into the regenerating tissues are thus relevant.

We evaluated MSC proliferation and we confirmed that WJ-MSC have a higher proliferation rate, results that were already reported by other authors [17,22,23]. This is expected since WJ-MSC are of fetal origin, and the cell proliferation decreases sharply with maturation of the donor. With a rare exception of the cryopreserved cells of the Wharton's Jelly for future use in which autologous cells may be available, their use is at present essentially dedicated to the allogeneic use. Nevertheless, their availability at the perinatal period may be considered in therapy of preterm birth, repair of inborn defects and in perinatal accidents, and, in view of their high protrophic and angiogenic capacity described in the present study, they may offer promising solutions [24,25].

The relatively high expression of CD54 and CD146 in WJ-MSC may be consistent with the proposal of their high potential in regenerative medicine. The CD54 (ICAM-1) is an adhesion molecule that upon stimulation with pro- inflammatory mediators promotes mobilization and transendothelial migration of circulating cells into injured tissues [26]. CD146 (MCAM, MUC18) is a cell adhesion molecule, whose high expression on MSC is associated with greater differentiation potential [27].

When considering an inflammatory profile, WJ-MSC secreted the highest concentrations of RANTES, MCP-1 and IP-10, chemokines able to attract a wide range of inflammatory cells (monocytes, macrophages, dendritic cells, T lymphocytes). IL-6 was secreted at higher concentrations by WJ-MSC, but all three cells secreted high IL-6 concentrations: while plasmatic concentration in healthy patients varied from 0.02 up to $10.1 \mathrm{pg} / \mathrm{mL}$ [28], IL-6 concentration in cell supernatants was much higher: $697.6 \pm$ $232.8 \mathrm{pg} / \mathrm{mL}$ for BM-MSC, $620.7 \pm 49.4$ for AT-MSC and $4,001.0 \pm 1,484.1$ for WJ-MSC. IL-6 was recently associated with MSC pluripotency and immunoprivilege: BMMSC differentiation induced loss of immune privilege and down-regulation of IL-6 secretion [29,30]. Nasir and colleagues demonstrated that a combination of BM-MSC and IL- 6 is much more effective in attenuating liver fibrosis than BM-MSC alone [31], and this result makes us suggest that maybe WJ-MSC alone would be a more appropriate candidate for this therapy, since these cells secrete higher IL-6 concentrations. 


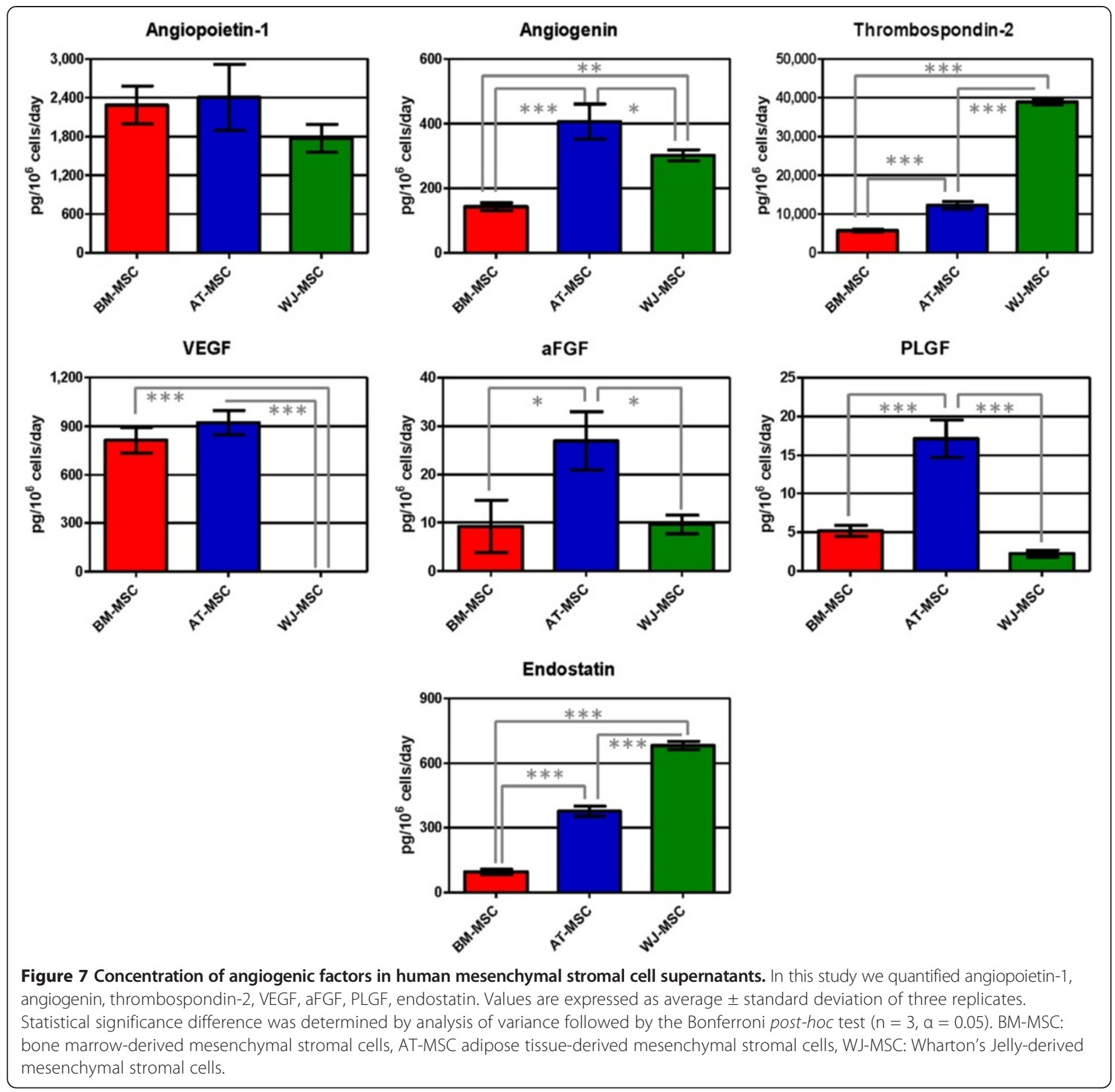

IL1-RA is an antagonist of the IL-1 receptor and belongs to the IL-1 cytokine family, a group of at least 11 inflammatory mediators. IL1-RA has already been described as a therapeutic candidate for diabetes mellitus II treatment, because of its protective effects: IL1-RA prevented pancreatic mononuclear cell infiltration, islet destruction and hyperglycemia in a model of induced diabetes mellitus [32]. In pre-clinical studies in mice, Ortiz and coworkers demonstrated that BM-MSC had an anti-inflammatory and anti-fibrotic effect and that this effect was mainly mediated by IL1-RA; they also demonstrated that BM-MSC were more effective than recombinant IL1-RA [33]. Therefore, this potential of WJ-MSC, mediated by IL1-RA secretion, should also be exploited.

IL-8 was secreted in very different concentrations among different cells: while BM-MSC secreted $47.8 \pm 11.7$ $\mathrm{pg} / 10^{6}$ cells/day, and WJ-MSC secreted 19,151.3 $\pm 5,512.2$ $\mathrm{pg} / 10^{6}$ cells/day, 400 times higher than BM-MSC production. A few authors reported increased IL-8 from MSC when cells were stimulated with lipopolysaccharides (LPS) [34], but identification of whether IL-8 secretion would be helpful in a determined MSC application needs to be studied.

Regarding angiogenic factors, only BM-MSC secreted detectable amounts of VEGF-D. VEGF-D was defined as 


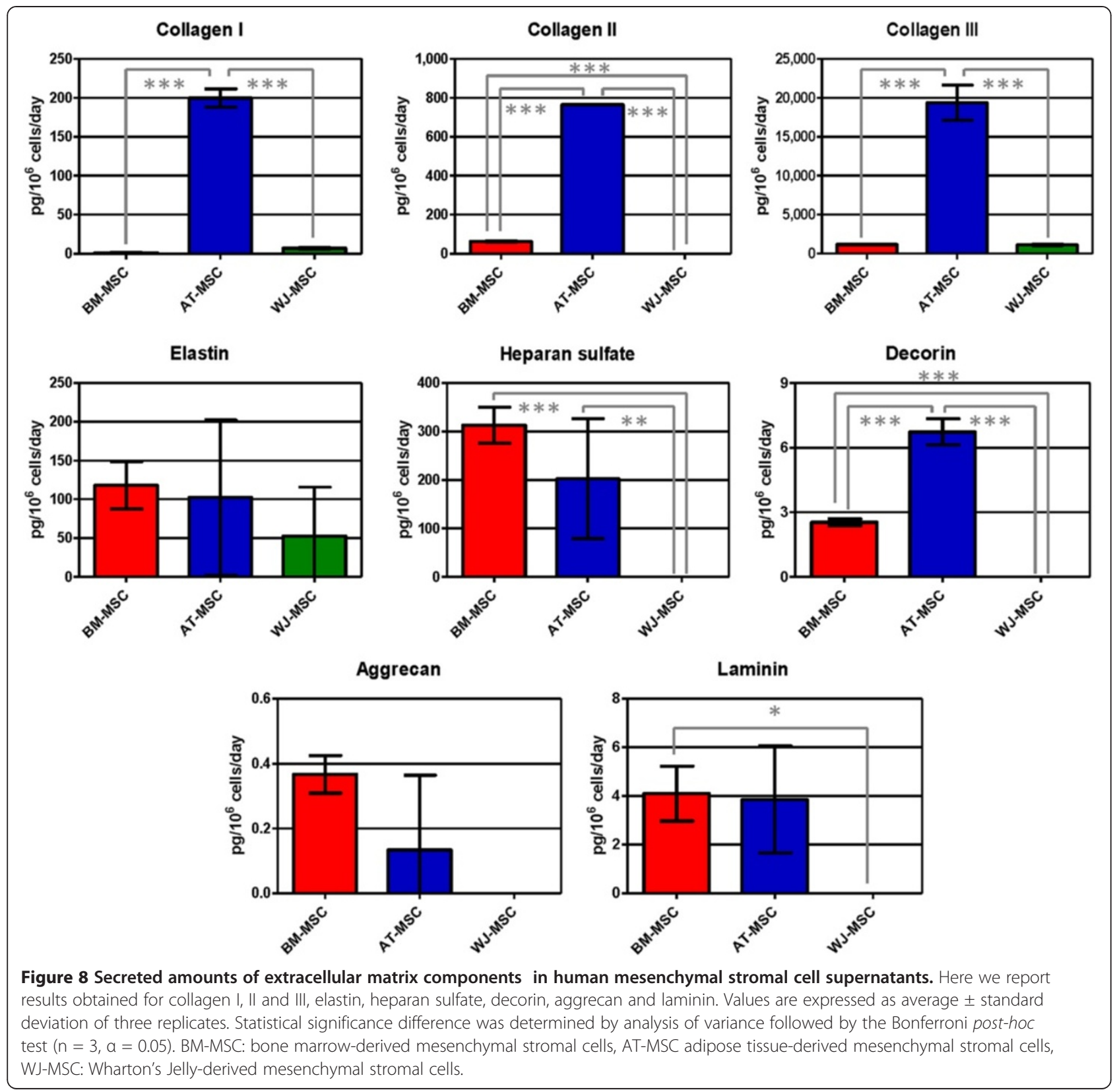

the strongest angiogenic and lymphangiogenic VEGF isoform [35] and it has been tested in phase I clinical trials for myocardial infarction in a gene therapy approach (ClinicalTrials.gov; Identifier: NCT01002430).

WJ-MSC produced almost undetectable amounts of VEGF; on the other hand, AT- and BM-MSC were the highest VEGF producers. Research articles like those published by Deuse's and Augustin's groups showed that MSC genetically modified to overexpress VEGF are more appropriate than MSC alone for treating acute myocardial infarction, as VEGF extended MSC survival and protected them against apoptosis and improved heart function recovery [36,37]. This information suggests that BM- and
AT-MSC would be better candidates for infarction therapy than WJ-MSC.

Thrombospondin-2 was another angiogenic factor that was found in high concentrations in all cell culture supernatants and WJ-MSC secreted the highest amounts. Jeong and colleagues have shown that WJ-MSC exerted a regenerative effect on cartilage and they suggested that this effect was mediated by thrombospondin-2, since this molecule alone could exert a similar effect and thrombospondin-2 knock-down in WJ-MSC using siRNA abolished its chondro-regenerative potential [38]. Considering that AT-MSC also secreted high concentrations of thrombospondin-2, they would be a good potential 


\section{MMP1}

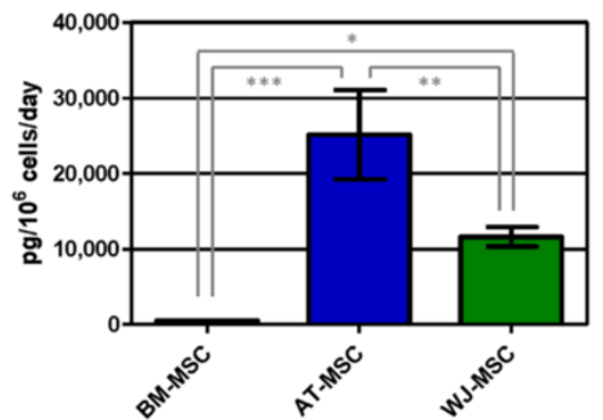

MMP3

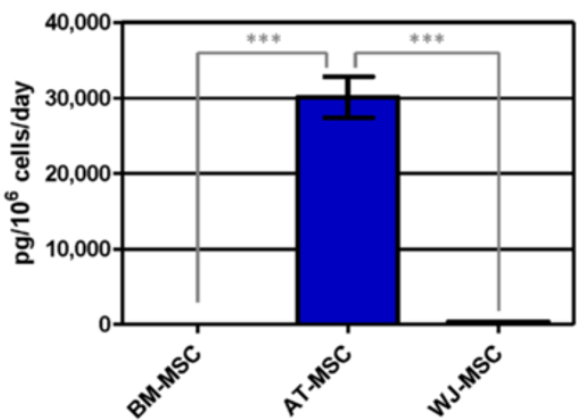

Figure 9 Concentration of secreted matrix metalloproteinases (MMP1 and MMP3) in human mesenchymal stromal cell supernatants. Values are expressed as average \pm standard deviation of three replicates. Statistical significance difference was determined by analysis of variance followed by the Bonferroni post-hoc test $(n=3, a=0.05)$. BM-MSC: bone marrow-derived mesenchymal stromal cells, AT-MSC adipose tissue-derived mesenchymal stromal cells, WJ-MSC: Wharton's Jelly-derived mesenchymal stromal cells.

candidate for cartilage regeneration, especially taking into account autologous adipose tissue availability in cases when the patients did not cryopreserve their own umbilical cord cells.

Angiopoietin-1 is an important pro-angiogenic factor involved in vascular maturation and neovasculogenesis. Similar to what was described for VEGF, genetically modified MSC expressing angiopoietin-1 were more effective in regenerating myocardial tissue after infarction than MSC alone [39]. Liu and coworkers also demonstrated that MSC expressed functional receptors for angiopoietin-1 and that angiopoietin-1 protected MSC against apoptosis induced by hypoxia and serum deprivation [40]. Angiopoietin-1 secretion was not statistically different for all three MSC, but the secretion rate of WJ-MSC was lower than those of AT- and BM-MSC.

PLGF displays a high homology with VEGF, binds to the VEGF receptor and is able to augment the action of VEGF both in vivo and in vitro. Liu and colleagues showed that PLGF exerted a neuroprotective and angiogenic effect in cerebral ischemia: BM-MSC injected intravenously reduced lesion volume and induced angiogenesis while improving functional recovery, but the effect was greater when BM-MSC were genetically modified to over-express PLGF [41]. Considering our results, AT-MSC secreted higher concentrations of PLGF: 3.3 and 7.8 times higher than BM- and WJ-MSC. This origin-related differential of AT-MSC would make them more appropriate for tissue regeneration after cerebral ischemia.

When analyzing growth factor secretion, WJ-MSC secreted higher amounts of TGF- $\beta 2$, HGF and PDGF-AA and was the only cell type secreting G-CSF in detectable levels. HGF promotes migration, proliferation and survival of a wide range of cell types and was shown to induce expression of cardiac-specific markers in MSC [42]. G-CSF is a potent chemotactic factor for MSC and has been successfully used in different applications, such as acute myocardial infarction [43] and injured brain [44].

Regarding extracellular matrix components, AT-MSC secreted the highest amounts of collagen I, II, III and IV and WJ-MSC did not secrete any detectable amounts of collagen II and IV. WJ-MSC did not produce fibronectin, heparan sulphate, decorin, laminin and aggrecan. Collagen II is the most abundant protein in articular and hyaline cartilage; therefore, WJ-MSC would not be appropriate for cartilage regeneration since it would generate a fibrous tissue due to its higher collagen III secretion. Collagen I and elastin are the main components of tendons, making AT-MSC the most appropriate cell type for tendon regeneration. MSC are also key players in skin regeneration and aging prevention: they are attracted by PDGF-BB secreted by endothelial cells and they increase collagen IV secretion, a component of basement membranes [45]. AT-MSC were the only cell type that secreted PDGF-BB in vitro and they produced the highest amounts of collagen IV, suggesting they are the most appropriate cell type for skin regeneration, since neither BM- nor WJ-MSC secreted PDGF-BB and collagen IV.

MMP1, MMP3 and MMP13 are important enzymes involved in the degradation of bone, cartilage and tendon. Serum and synovial levels of MMP1, MMP3 and MMP13 are increased in rheumatoid arthritis and osteoarthritis $[46,47]$. Analyzing our results, AT-MSC produced the highest concentrations of MMP1 and MMP3, this being a negative point for using AT-MSC in bone, cartilage and tendon applications. AT- and WJ-MSC secreted high amounts of MMP1 and MMP3, but low levels or no MMP13. A good candidate for bone, cartilage and tendon regeneration, when considering matrix metalloproteinases, would be BM-MSC, which secreted the lowest concentrations of MMP1 and MMP3 and no MMP13. 
In summary, WJ-MSC showed a higher pro-inflammatory and mitogenic profile, while AT-MSC secreted higher concentrations of pro-angiogenic proteins, extracellular matrix components and matrix metalloproteinases. Acquiring a deeper molecular knowledge about MSC from different origins will help us make a more rational and effective selection of the MSC for different applications in regenerative medicine.

\section{Conclusions}

Our data showed that MSC from different tissues have different properties in vitro and this can be the reason for their different behavior in different clinical applications. In conclusion, cell type for regenerative therapies should be carefully chosen. The present results need to be compared with in vivo pre-clinical studies in order to suggest the best protocols for mesenchymal stromal cell use in each clinical therapy.

\section{Additional file}

Additional file 1: Table S1. Protein concentration in human mesenchymal stromal cell supernatants. Results are expressed in expressed in mean $\mathrm{pg} / 10^{6}$ cells/day \pm standard deviation of three replicates. BM-MSC: bone marrow-derived mesenchymal stromal cells, ATMSC adipose tissue-derived mesenchymal stromal cells, WJ-MSC: Wharton's Jelly-derived mesenchymal stromal cells.

\section{Abbreviations}

aFGF: Acidic fibroblast growth factor; AT-MSC: Adipose tissue-derived MSC; bFGF: Basic fibroblast growth factor; BM-MSC: Bone marrow-derived MSC; DMEM: Dulbecco's modified Eagle media; EGF: Endothelial growth factor; FBS: Fetal bovine serum; FCS: Forward scatter; G-CSF: Granulocyte colonystimulating factor; GM-CSF: Granulocyte macrophage colony-stimulating factor; HGF: Hepatocyte growth factor; IFN: Interferon; IGF-1: Insulin growth factor 1; IL: Interleukin; IP-10: Interferon gamma-induced protein 10; LG-DMEM: Low-glucose DMEM; MCP-1: Monocyte chemoattractant protein-1; MEM: Minimum essential media; MIG: Monokine induced by IFN-gamma; MIP-1: Macrophage inflammatory protein 1; MMP: Matrix metalloproteinase; MSC: Mesenchymal stromal cells; PBS: Phosphate-buffered saline;

PDGF: Platelet-derived growth factor; PLGF: Placental growth factor; RANTES: Regulated on activation, normal T cell expressed and secreted; SSC: Side scatter; TGF: Transforming growth factor; TNF-a: Tumor necrosis factor alpha; VEGF: Vascular endothelial growth factor; WJ-MSC: Wharton's jelly-derived MSC.

\section{Competing interests}

PRA, MVTT, RBVC and RB are employees at Excellion Biomedical Services S.A. Results reported here have no connections or influence on the company's products. The authors declared that no competing financial and/or private interests exist.

\section{Authors' contributions}

PRA, MVIT, RBVC, RB and JMG participated in the conception and design of the study. PRA, RBVC and MVTT performed the experiments, collected and analyzed the data. PRA performed the statistical analysis and wrote the manuscript. MTW and RBVC revised the manuscript. JMG and RB revised and approved the final manuscript. All authors read and approved the final manuscript.

\section{Acknowledgements}

The authors thank professor Gutemberg Alves from the Clinical Research Unit, Antônio Pedro Hospital, Fluminense Federal University (Niterói, Rio de Janeiro, Brazil) for the support with the Luminex assays.

\section{Author details}

${ }^{1}$ Excellion Biomedical Services S.A, Rua Afrânio de Mello Franco 333, 25651000 PetrópolisRio de Janeiro, Brazil. ²National Institute of Metrology, Quality and Technology (Inmetro), Xerém, RJ, Brazil.

Received: 13 December 2013 Revised: 7 March 2014

Accepted: 1 April 2014 Published: 16 April 2014

\section{References}

1. Crisan M, Yap S, Casteilla L, Chen CW, Corselli M, Park TS, Andriolo G, Sun B, Zheng B, Zhang L, Norotte C, Teng PN, Traas J, Schugar R, Deasy BM, Badylak S, Buhring HJ, Giacobino JP, Lazzari L, Huard J, Péault B: A perivascular origin for mesenchymal stem cells in multiple human organs. Cell Stem Cell 2008, 13:301-313.

2. Friedenstein J, Chailakhjan RK, Lalykina KS: The development of fibroblast colonies in monolayer cultures of guinea-pig bone marrow and spleen cells. Cell Tissue Kinet 1970, 3:393-403.

3. Zuk PA, Zhu M, Mizuno H, Huang J, Futrell JW, Katz AJ, Benhaim P, Lorenz HP, Hedrick MH: Multilineage cells from human adipose tissue: implications for cell-based therapies. Tissue Eng 2001, 7:211-228.

4. Miao Z, Jin J, Chen L, Zhu J, Huang W, Zhao J, Qian H, Zhang X: Isolation of mesenchymal stem cells from human placenta: comparison with human bone marrow mesenchymal stem cells. Cell Biol Int 2006, 30:681-687.

5. Griffiths MJ, Bonnet D, Janes SM: Stem cells of the alveolar epithelium. Lancet 2005, 366:249-260.

6. Wang HS, Hung SC, Peng ST, Huang CC, Wei HM, Guo YJ, Fu YS, Lai MC, Chen CC: Mesenchymal stem cells in the Wharton's jelly of the human umbilical cord. Stem Cells 2004, 22:1330-1337.

7. De Bari C, Dell'Accio F, Tylzanowski P, Luyten FP: Multipotent mesenchymal stem cells from adult human synovial membrane. Arthritis Rheum 1928-1942, 2001:44.

8. Gronthos S, Mankani M, Brahim J, Robey PG, Shi S: Postnatal human dental pulp stem cells (DPSCs) in vitro and in vivo. Proc Natl Acad Sci U S A 2000, 97:13625-13630.

9. Kholodenko IV, Konieva AA, Kholodenko RV, Yarygin KN: Molecular mechanisms of migration and homing of intravenously transplanted mesenchymal stem cells. J Regen Med Tissue Eng 2013, 2:4-11.

10. Galindo LT, Filippo TR, Semedo P, Ariza CB, Moreira CM, Camara NO, Porcionatto MA: Mesenchymal stem cell therapy modulates the inflammatory response in experimental traumatic brain injury. Neurol Res Int 2011, 2011:564089.

11. Nivet E, Vignes M, Girard SD, Pierrisnard C, Baril N, Devèze A, Magnan J, Lanté F, Khrestchatisky M, Féron F, Roman FS: Engraftment of human nasal olfactory stem cells restores neuroplasticity in mice with hippocampal lesions. J Clin Invest 2011, 121:2808-2820.

12. Lee JS, Hong JM, Moon GJ, Lee PH, Ahn YH: Bang OY; STARTING collaborators: A long-term follow-up study of intravenous autologous mesenchymal stem cell transplantation in patients with ischemic stroke. Stem Cells 2012, 28:1099-1106.

13. Le Blanc K, Tammik C, Rosendahl K, Zetterberg E, Ringdén O: HLA expression and immunologic properties of differentiated and undifferentiated mesenchymal stem cells. Exp Hemato/ 2003, 31:890-896.

14. Ryan JM, Barry FP, Murphy JM, Mahon BP: Mesenchymal stem cells avoid allogeneic rejection. J Inflamm (Lond) 2005, 2:8.

15. Al-Nbaheen M, Vishnubalaji R, Ali D, Bouslimi A, Al-Jassir F, Megges M, Prigione A, Adjaye J, Kassem M, Aldahmash A: Human stromal (mesenchymal) stem cells from bone marrow, adipose tissue and skin exhibit differences in molecular phenotype and differentiation potential. Stem Cell Rev 2013, 9:32-43.

16. Sakaguchi Y, Sekiya I, Yagishita K, Muneta T: Comparison of human stem cells derived from various mesenchymal tissues: superiority of synovium as a cell source. Arthritis Rheum 2005, 52:2521-2529.

17. Wang L, Tran I, Seshareddy K, Weiss ML, Detamore MS: A comparison of human bone marrow-derived mesenchymal stem cells and human umbilical cord-derived mesenchymal stromal cells for cartilage tissue engineering. Tissue Eng Part A 2009, 15:2259-2266

18. Ramkisoensing AA, Pijnappels DA, Askar SFA, Passier R, Swildens J, Goumans MJ, Schutte Cl, de Vries AA, Scherjon S, Mummery CL, Schalij MJ, Atsma D: Human embryonic and fetal mesenchymal stem cells differentiate toward three different cardiac lineages in contrast to their adult counterparts. PLOS ONE 2011, 6:e24164. 
19. Hsieh JY, Wang HW, Chang SJ, Liao KH, Lee IH, Li WS, Wu CH, Lin WY, Cheng SM: Mesenchymal stem cells from human umbilical cord express preferentially secreted factors related to neuroprotection, neurogenesis, and angiogenesis. PLOS ONE 2013, 8:e72604.

20. Naftali-Shani N, Itzhaki-Alfia A, Landa-Rouben N, Kain D, Holbova R, Adutler-Lieber S, Molotski N, Asher E, Grupper A, Millet E, Tessone A, Winkler E, Kastrup J, Feinberg MS, Zipori D, Pevsner-Fischer M, Raanani E, Leor J: The origin of human mesenchymal stromal cells dictates their reparative properties. J Am Heart Assoc 2013, 2:e000253.

21. Amable PR, Teixeira MV, Carias RB, Granjeiro JM, Borojevic R: Identification of appropriate reference genes for human mesenchymal cells during expansion and differentiation. PLoS One 2013, 8:e73792.

22. Hsieh JY, Fu YS, Chang SJ, Tsuang YH, Wang HW: Functional module analysis reveals differential osteogenic and stemness potentials in human mesenchymal stem cells from bone marrow and Wharton's jelly of umbilical cord. Stem Cells Dev 1895-1910, 2010:19.

23. Deuse T, Stubbendorff M, Tang-Quan K, Phillips N, Kay MA, Eiermann T, Phan $\Pi$, Volk HD, Reichenspurner H, Robbins RC, Schrepfer S: Immunogenicity and immunomodulatory properties of umbilical cord lining mesenchymal stem cells. Cell Transplant 2011, 20:655-667.

24. Borghesi A, Cova C, Gazzolo D, Stronati M: Stem cell therapy for neonatal diseases associated with preterm birth. J Clin Neonatol 2013, 2:1-7

25. Messerli M, Wagner A, Sager R, Mueller M, Baumann M, Surbek DV, Schoeberlein A: Stem cells from umbilical cord Wharton's jelly from preterm birth have neuroglial differentiation potential. Reprod Sci 2013, 20:1455-1464

26. Yang L, Froio RM, Sciuto TE, Dvorak AM, Alon R, Luscinskas FW: ICAM-1 regulates neutrophil adhesion and transcellular migration of TNF-alphaactivated vascular endothelium under flow. Blood 2005, 106:584-592.

27. Russell KC, Phinney DG, Lacey MR, Barrilleaux BL, Meyertholen KE, O'Connor $\mathrm{KC}$ : In vitro high-capacity assay to quantify the clonal heterogeneity in trilineage potential of mesenchymal stem cells reveals a complex hierarchy of lineage commitment. Stem Cells 2010, 28:788-798.

28. Ridker PM, Rifai N, Stampfer MJ, Hennekens CH: Plasma concentration of interleukin- 6 and the risk of future myocardial infarction among apparently healthy men. Circulation 2000, 101:1767-1772.

29. Li P, Li SH, Wu J, Zang WF, Dhingra S, Sun L, Weisel RD, Li RK: Interleukin-6 downregulation with mesenchymal stem cell differentiation results in loss of immunoprivilege. J Cell Mol Med 2013, 17:1136-1145.

30. Pricola KL, Kuhn NZ, Haleem-Smith H, Song Y, Tuan RS: Interleukin-6 maintains bone marrow-derived mesenchymal stem cell stemness by an ERK1/2-dependent mechanism. J Cell Biochem 2009, 108:577-588.

31. Nasir GA, Mohsin S, Khan M, Shams S, Ali G, Khan SN, Riazuddin S: Mesenchymal stem cells and interleukin- 6 attenuate liver fibrosis in mice. J Trans/ Med 2013, 11:78.

32. Sandberg JO, Andersson A, Eizirik DL, Sandler S: Interleukin-1 receptor antagonist prevents low dose streptozotocin induced diabetes in mice. Biochem Biophys Res Commun 1994, 202:543-548.

33. Ortiz LA, Dutreil M, Fattman C, Pandey AC, Torres G, Go K, Phinney DG Interleukin 1 receptor antagonist mediates the antiinflammatory and antifibrotic effect of mesenchymal stem cells during lung injury. Proc Natl Acad Sci U S A 2007, 104:11002-11007.

34. Kilroy GE, Foster SJ, Wu X, Ruiz J, Sherwood S, Heifetz A, Ludlow JW, Stricker DM, Potiny S, Green P, Halvorsen YD, Cheatham B, Storms RW, Gimble JM: Cytokine profile of human adipose-derived stem cells: expression of angiogenic, hematopoietic, and pro-inflammatory factors. J Cell Physiol 2007, 212:702-709

35. Rissanen TT, Markkanen JE, Gruchala M, Heikura T, Puranen A, Kettunen MI, Kholová I, Kauppinen RA, Achen MG, Stacker SA, Alitalo K, Ylä-Herttuala S: VEGF-D is the strongest angiogenic and lymphangiogenic effector among VEGFs delivered into skeletal muscle via adenoviruses. Circ Res 2003, 92:1098-1106.

36. Deuse T, Peter C, Fedak PW, Doyle T, Reichenspurner H, Zimmermann WH, Eschenhagen T, Stein W, Wu JC, Robbins RC, Schrepfer S: Hepatocyte growth factor or vascular endothelial growth factor gene transfer maximizes mesenchymal stem cell-based myocardial salvage after acute myocardial infarction. Circulation 2009, 120:S247-S254.

37. Augustin M, Mahar MA, Lakkisto P, Tikkanen I, Vento A, Pätilä T, Harjula A: VEGF overexpression improves mesenchymal stem cell sheet transplantation therapy for acute myocardial infarction. J Tissue Eng Regen Med 2013, 7:742-750.
38. Jeong SY, Kim DH, Ha J, Jin HJ, Kwon SJ, Chang JW, Choi SJ, Oh W, Yang YS, Kim G, Kim JS, Yoon JR, Cho DH, Jeon HB: Thrombospondin-2 secreted by human umbilical cord blood-derived mesenchymal stem cells promotes chondrogenic differentiation. Stem Cells 2013, 31:2136-2148.

39. Paul A, Nayan M, Khan AA, Shum-Tim D, Prakash S: Angiopoietin-1-expressing adipose stem cells genetically modified with baculovirus nanocomplex: investigation in rat heart with acute infarction. Int J Nanomedicine 2012, 7:663-682.

40. Liu XB, Jiang J, Gui C, Hu XY, Xiang MX, Wang JA: Angiopoietin-1 protects mesenchymal stem cells against serum deprivation and hypoxia-induced apoptosis through the PI3K/Akt pathway. Acta Pharmacol Sin 2008, 29:815-822.

41. Liu H, Honmou O, Harada K, Nakamura K, Houkin K, Hamada H, Kocsis JD: Neuroprotection by PIGF gene-modified human mesenchymal stem cells after cerebral ischaemia. Brain 2006, 129:2734-2745.

42. Forte G, Minieri M, Cossa P, Antenucci D, Sala M, Gnocchi V, Fiaccavento R, Carotenuto F, De Vito P, Baldini PM, Prat M, Di Nardo P: Hepatocyte growth factor effects on mesenchymal stem cells: proliferation, migration, and differentiation. Stem Cells 2006, 24:23-33.

43. Kawada H, Fujita J, Kinjo K, Matsuzaki Y, Tsuma M, Miyatake H, Muguruma Y, Tsuboi K, Itabashi Y, Ikeda Y, Ogawa S, Okano H, Hotta T, Ando K, Fukuda K: Nonhematopoietic mesenchymal stem cells can be mobilized and differentiate into cardiomyocytes after myocardial infarction. Blood 2004, 104:3581-3587.

44. Deng J, Zou ZM, Zhou TL, Su YP, Ai GP, Wang JP, Xu H, Dong SW: Bone marrow mesenchymal stem cells can be mobilized into peripheral blood by G-CSF in vivo and integrate into traumatically injured cerebral tissue. Neurol Sci 2011, 32:641-651.

45. Soma T, Yamanishi H, Ishimatsu-Tsuji Y, Fujiwara S: Role of PDGF-BB in the behavior of mesenchymal stem cells in human skin. J Invest Dermatol 2012, 132:S135-S148.

46. Lindy O, Konttinen YT, Sorsa T, Ding Y, Santavirta S, Ceponis A, López-Otín C: Matrix metalloproteinase 13 (collagenase 3 ) in human rheumatoid synovium. Arthritis Rheum 1997, 40:1391-1399.

47. Mahmoud RK, El-Ansary AK, El-Eishi HH, Kamal HM, El-Saeed NH: Matrix metalloproteinases MMP-3 and MMP-1 levels in sera and synovial fluids in patients with rheumatoid arthritis and osteoarthritis. Ital J Biochem 2005, 54:248-257.

\section{doi: $10.1186 /$ scrt442}

Cite this article as: Amable et al:: Protein synthesis and secretion in human mesenchymal cells derived from bone marrow, adipose tissue and Wharton's jelly. Stem Cell Research \& Therapy 2014 5:53.

\section{Submit your next manuscript to BioMed Central and take full advantage of:}

- Convenient online submission

- Thorough peer review

- No space constraints or color figure charges

- Immediate publication on acceptance

- Inclusion in PubMed, CAS, Scopus and Google Scholar

- Research which is freely available for redistribution 